\title{
Papers
}

\section{Adverse drug reactions as cause of admission to hospital: prospective analysis of 18820 patients}

\author{
Munir Pirmohamed, Sally James, Shaun Meakin, Chris Green, Andrew K Scott, Thomas J Walley, \\ Keith Farrar, B Kevin Park, Alasdair M Breckenridge
}

\begin{abstract}
Objective To ascertain the current burden of adverse drug reactions (ADRs) through a prospective analysis of all admissions to hospital.

Design Prospective observational study.

Setting Two large general hospitals in Merseyside, England.

Participants 18820 patients aged $>16$ years admitted over six months and assessed for cause of admission.

Main outcome measures Prevalence of admissions due to an ADR, length of stay, avoidability, and outcome.

Results There were 1225 admissions related to an $\mathrm{ADR}$, giving a prevalence of $6.5 \%$, with the $\mathrm{ADR}$ directly leading to the admission in $80 \%$ of cases. The median bed stay was eight days, accounting for $4 \%$ of the hospital bed capacity. The projected annual cost of such admissions to the NHS is $£ 466 \mathrm{~m}(€ 706 \mathrm{~m}$, $\$ 847 \mathrm{~m}$ ). The overall fatality was $0.15 \%$. Most reactions were either definitely or possibly avoidable. Drugs most commonly implicated in causing these admissions included low dose aspirin, diuretics, warfarin, and non-steroidal anti-inflammatory drugs other than aspirin, the most common reaction being gastrointestinal bleeding.

Conclusion The burden of ADRs on the NHS is high, accounting for considerable morbidity, mortality, and extra costs. Although many of the implicated drugs have proved benefit, measures need to be put into place to reduce the burden of ADRs and thereby further improve the benefit:harm ratio of the drugs.
\end{abstract}

\section{Introduction}

Lazarou and colleagues suggested that adverse drug reactions (ADRs) caused over 100000 deaths in the United States in 1994. ${ }^{1}$ However, this study was criticised for various reasons, including that the death rate was extrapolated from admission rates in 1994, yet based on rates of ADRs taken from studies conducted before $1981 .^{2}$ Publication bias may have also contributed to what many investigators regard as inflated mortality data.

There are few recent data on epidemiology of ADRs. ${ }^{3}$ In the United Kingdom, most studies were performed 10 to 30 years ago and were relatively small, often confined to individual units such as for care of the elderly. ${ }^{4-11}$ The largest UK study was based on retrospective review of case notes, ${ }^{12}$ and, given the poor documentation of ADRs in medical case notes, it probably underestimated the impact. Of the two most recent UK studies, one concentrated on an acute medical admissions unit, ${ }^{13}$ while another had broad inclusion criteria for drug related admissions, including overdoses. ${ }^{14}$ Given the changes in medical practice over the past two decades, more recent estimates of the burden of ADRs on hospitals are needed. We undertook a prospective analysis of admissions caused by ADRs in two large UK hospitals to define prevalence and outcome and to assess causality and preventability.

\section{Methods}

The study was conducted from November 2001 to April 2002 in two NHS hospitals in Merseyside: hospital A-a teaching hospital serving a population of 300 000-and hospital B-a district general hospital, serving a population of 330000 . To ensure that there was consistency between the two sites, in hospital B, we excluded patients aged $<16$ years and women presenting with obstetric or gynaecological complaints.

We assessed every patient aged over 16 years who was admitted over the six month period to determine if the admission had been caused by an ADR. Most patients were admitted through either the accident and emergency department or the acute medical and surgical assessment units. The definition of ADR used was that of Edwards and Aronson. ${ }^{15}$ We did not include any patients with either deliberate or unintentional overdose or those who relapsed because of noncompliance. Patients were categorised as having an ADR by either SM (in hospital A) or SJ (in hospital B) if the cause of admission was consistent with the known adverse effect profile of the drug (according to the British National Formulary ${ }^{16}$ ), if there was temporal relation with the start of drug therapy, and if, after appropriate investigations, other causes were excluded. When the drug history was unclear, we interviewed the patients or relatives or obtained further details from the general practitioner. All patients initially categorised as having an ADR were assessed again by two or
Department of Pharmacology and Therapeutics, University of Liverpool,

Liverpool L69 3GE

Munir Pirmohamed professor of clinical pharmacology

Thomas J Walley professor of clinical pharmacology B Kevin Park professor of pharmacology

Alasdair M Breckenridge professor of clinical pharmacology Royal Liverpool University Hospital, Liverpool L7 8XP

Shaun Meakin research nurse

Chris Green senior pharmacist

Wirral Hospitals NHS Trust, Wirral CH49 5PE

Sally James research pharmacist Andrew K Scott consultant in care of the elderly

Keith Farrar

chief pharmacist

Correspondence to: M Pirmohamed munirp@liv.ac.uk

BMJ 2004;329:15-19 
Table 1 Assessment of causality of all admissions related to adverse drug reaction. Figures are numbers (percentages) of admissions

\begin{tabular}{|c|c|c|c|c|c|c|}
\hline & \multicolumn{3}{|c|}{ Naranjo method ${ }^{14}$} & \multicolumn{3}{|c|}{ Jones method ${ }^{15}$} \\
\hline & Definite & Probable & Possible & $\begin{array}{c}\text { Highly } \\
\text { probable }\end{array}$ & Probable & Possible \\
\hline Hospital A ( $\mathrm{n}=564)$ & $4(0.7)$ & $392(69.5)$ & 168 (29.8) & $2(0.4)$ & 315 (55.9) & $247 \quad(43.8)$ \\
\hline Hospital B ( $n=661)$ & 19 (2.9) & $450(68.1)$ & $192(29.0)$ & $4(0.6)$ & 437 (66.1) & $220(33.2)$ \\
\hline
\end{tabular}

three of the authors, who met to reach a consensus decision and exclude doubtful cases $(\mathrm{n}=30,2.4 \%)$. MP undertook a further review of all $\mathrm{ADR}$ cases to ensure correct categorisation. Assessment of causality was also performed for all cases using the methods of Naranjo et $\mathrm{al}^{17}$ and Jones. ${ }^{18}$ To ensure that patients with ADRs had not been missed, from each hospital we analysed 200 random case notes (400 in total) of patients categorised as not having had an ADR. All assessments were performed by staff with training in drug safety, including specialists in clinical pharmacology and general medicine, pharmacy, geriatrics, and nursing.

Where the patient was categorised as having an $\mathrm{ADR}$, we recorded all drug details, the nature of the reaction, the outcome, the total time spent in hospital, and any invasive investigations performed. In addition, we determined the type of ADR (according to the classification of Rawlins and Thompson ${ }^{19}$ ) and whether it was due to an interaction (according to the interactions listed in the summary of product characteristics or relevant literature, or both)

We assessed avoidability of the ADRs using the definitions developed by Hallas et al, ${ }^{20}$ as follows:

- Definitely avoidable - the ADR was due to a drug treatment procedure inconsistent with present day knowledge of good medical practice

- Possible avoidable-the ADR could have been avoided by an effort exceeding the obligatory demands of present day knowledge of good medical practice

- Unavoidable-the ADR could not have been avoided by any reasonable means.

\section{Statistical analysis}

Statistical analysis was performed with the StatsDirect statistical software program (version 1.9.8). The results are presented either as medians and interquartile ranges or percentage frequencies and 95\% confidence intervals, as appropriate. Statistical analysis was performed with the Mann-Whitney $\mathrm{U}$ test for all data, except for proportions, which were analysed by the $\mathrm{z}$ test. A P value $<0.05$ was regarded as being significant.

\section{Results}

Over six months there were 18820 admissions (7911 in hospital A; 10909 in hospital B). Events judged as being due to an ADR caused 1225 (6.5\%, 95\% confidence interval $6.2 \%$ to $6.9 \%$ ) admissions. Patients admitted with ADRs (median age 76 years, interquartile range 65-83) were significantly older than patients without ADRs (66 years, 46-79; 95\% confidence interval for difference 8 years to 10 years, $\mathrm{P}<0.0001)$. The proportion of women in the ADR group (59\%) was significantly higher than in the non-ADR group (52\%; $\mathrm{z}=4.9 ; 4 \%$ to $10 \%, \mathrm{P}<0.0001)$. The admission rate for ADR in hospital A $(n=564,7.1 \%)$ was slightly but significantly higher than in hospital $\mathrm{B}(\mathrm{n}=661,6.1 \%$; $\mathrm{z}=3.0, \quad 0.4 \%$ to $1.8 \% ; \mathrm{P}=0.003$ ). Eighty percent $(\mathrm{n}=980 ; 78 \%$ to $82 \%)$ of the ADRs were judged to have been directly responsible for the admission (termed "causal"), while $20 \%(\mathrm{n}=245,18 \%$ to $22 \%)$ were identified through screening (termed "coincidental"), and, although not directly responsible for the admission, may nevertheless have contributed to it. Most ADRs ( $\mathrm{n}=1161,95 \%, 93 \%$ to $96 \%)$ were classified as type A ADRs, according to the classification of Rawlins and Thompson. ${ }^{19}$ In our review of 400 admissions categorised as not being related to an ADR we did not identify any misclassified patients, indicating that the proportion of false negatives was probably below $1 / 133$.

We determined avoidability of admissions related to an ADR by the method of Hallas et al. ${ }^{20}$ Only 340 $(28 \%, 25 \%$ to $30 \%)$ of the ADR were assessed as unavoidable, while 107 (9\%, 7\% to 10\%) and 773 (63\%, $60 \%$ to $66 \%$ ) were classified as "definitely avoidable" and "possibly avoidable," respectively. Thus, we classified $72 \%$ of ADRs as avoidable.

We used two forms of assessment of causality for all admissions categorised as due to an ADR. ${ }^{17}{ }^{18}$ Most admissions were classified as "probable" (table 1). There was agreement between the two assessments in $1069(87 \%)$ of the admissions.

Table 2 shows the outcome of the patients admitted with ADRs. Although most patients recovered, 28 (2.3\%) died as a direct result of the index ADR (as detailed in either the case notes or on the death certificate). Gastrointestinal bleeding was responsible for 15 $(54 \%)$ deaths (table 3 ), while aspirin, in isolation or in combination with other drugs, was implicated in 17 $(61 \%)$ deaths. ADRs were therefore responsible for the death of $0.15 \%(0.1 \%$ to $0.2 \%)$ of all the patients admitted.

Patients admitted with an ADR had a median stay of eight days (interquartile range 4-18 days), and the total bed occupancy in the two hospitals was substantial (table 2). The cost of this at average costs per medical bed day (£228; €343, \$414) $)^{21}$ would be $£ 466 \mathrm{~m}(€ 706 \mathrm{~m}, \$ 847 \mathrm{~m})$ a year.

Table 4 lists the drugs implicated in causing ADRs. Non-steroidal anti-inflammatory drugs (NSAIDs) and diuretics were most commonly implicated. Aspirin was the most common drug, implicated in $18 \%$ of admissions. In these admissions $162(74 \%)$ patients were taking a dose of $75 \mathrm{mg}$ daily. Gastrointestinal bleeding was the most common adverse effect, occurring in 157 (72\%) of all aspirin related admissions.

Interactions were responsible for ADRs in 88 (15.6\%, 13\% to $19 \%)$ and $115(17.4 \%, 15 \%$ to $21 \%)$ of the admissions in hospitals $\mathrm{A}$ and $\mathrm{B}$, respectively. Overall, interactions accounted for $16.6 \%$ (15\% to $19 \%)$ of ADRs. Examples of interactions included aspirin with warfarin causing gastrointestinal bleeding, aspirin with other NSAIDs leading to gastrointestinal adverse

Table 2 Outcome of patients admitted to hospital with adverse drug reaction

\begin{tabular}{lcc} 
& Hospital A & Hospital B \\
\hline No (\%) who recovered & $555(98.4)$ & $642(97.1)$ \\
\hline No (\%) who died & $9(1.6)$ & $19(2.9)$ \\
\hline Bed days over six months & 7659 & 9793 \\
\hline$\%$ bed days over one year & 3.5 & 4.4 \\
\hline
\end{tabular}


Table 3 Details of deaths caused by adverse drug reactions

\begin{tabular}{lcl} 
Adverse drug reaction & $\begin{array}{c}\text { No of } \\
\text { deaths }\end{array}$ & \multicolumn{1}{c}{ Drugs (No of deaths) } \\
\hline Gastrointestinal bleeding & 15 & $\begin{array}{l}\text { Aspirin (6), aspirin and dipyridamole (2), aspirin and diclofenac (1), aspirin and rofecoxib (1), aspirin and meloxicam (1) } \\
\text { aspirin and fluoxetine (1), diclofenac and prednisolone (1), paroxetine (1), warfarin (1) }\end{array}$ \\
\hline Perforated duodenal ulcer & 2 & Aspirin and diclofenac (1), diclofenac (1) \\
\hline Intracranial haemorrhage & 5 & Aspirin (2), aspirin and diclofenac (1), aspirin and warfarin (1), warfarin (1) \\
\hline Renal failure & 5 & $\begin{array}{l}\text { Enalapril and furosemide (1), spironolactone, furosemide and captopril (1), captopril and bumetanide (1), ramipril (1), } \\
\text { co-amilofruse and calcium carbonate (Calcichew) (1, included hypercalcaemia) }\end{array}$ \\
\hline Lithium toxicity & 1 & Lithium \\
\hline
\end{tabular}

effects, renal failure associated with the use of combinations of diuretics or the concomitant use of diuretics and ACE inhibitors, and increased anticoagulation and digoxin toxicity through coprescription of interacting drugs.

\section{Discussion}

We have undertaken the largest prospective analysis in the United Kingdom of adverse drug reactions (ADRs) as a cause of admission to hospital. Our data show that up to $6.5 \%$ or $5.2 \%$ (if the fifth of ADRs detected coincidently are excluded) of all admissions are related to ADRs. This is similar to the $5 \%$ estimate based on pooled data from several studies worldwide..$^{22}$ Many of the studies included in recent systematic reviews, however, are more than 20 years old, ${ }^{132324}$ and it is disappointing that the burden of ADRs has not decreased.

\section{Study design-strengths and weaknesses}

The advantages of our study over earlier work include the prospective nature and size, which allowed a more accurate recording of both the drug history and symptoms, and the assessment of causality. However, as with any other study of this nature, there is a potential weakness in that assignment of an admission as being related to an ADR is subject to clinical judgment, which may vary between individuals. To overcome this, we assessed all patients at least twice, and we subjected all the cases to two validated assessments of causality, ${ }^{17} 18$ which showed a high degree of agreement. Nevertheless, it is impossible to be absolutely certain of a causal link between a drug and an ADR. For example, with low dose aspirin, up to half of the cases of bleeding may have occurred anyway, irrespective of aspirin use. ${ }^{25}$
However, it is important to remember that such figures are derived from population based studies and such assessment is not always possible in individual patients.

Burden of ADRs on bed occupancy and cost Patients with an ADR stayed a median of eight days. Extrapolating this to the whole NHS bed base in England for patients aged $>16$ years suggests that at any one time the equivalent of up to seven 800 bed hospitals may be occupied by patients admitted with ADRs. This is higher than the estimate in a recent systematic review (four to six 400 bed hospitals), ${ }^{3}$ which was based on shorter hospital stays derived from smaller studies. However, it is important to exercise caution in interpreting this estimate of bed use as it is based on extrapolation from two hospitals to the whole NHS bed base, we were not able to determine the causative fractions for all the implicated drugs, and the estimate does not take into account the bed days saved through the beneficial effects of the drugs.

Our data suggest that admissions related to ADRs cost the NHS up to $£ 466 \mathrm{~m}$ annually. Although estimates of costs in the literature vary, ${ }^{26}$ on a per capita basis our figure is comparable with the lower estimates from the United States ${ }^{27} 28$ and also with a total costs estimated in a recent UK systematic review. ${ }^{3}$ Further detailed analysis, however, is required to provide more accurate figures.

\section{Drugs implicated in ADRs}

Lazarou et al suggested that ADRs, based on a death rate of $0.32 \%$, caused over 100000 deaths in the United States. ${ }^{1}$ This figure was based on a $0.13 \%$ incidence of fatal ADRs in patients admitted to hospital, and $0.19 \%$ in patients developing an ADR while in

\begin{tabular}{|c|c|c|c|}
\hline Drug group/drug & No $(\%)$ of cases & Individual drugs & Adverse reactions \\
\hline NSAIDs & $363(29.6)$ & $\begin{array}{l}\text { Aspirin (218), diclofenac (52), ibuprofen (34), } \\
\text { rofecoxib (33), celecoxib (8), ketoprofen (6) naproxen } \\
\text { (5) }\end{array}$ & $\begin{array}{l}\text { GI bleeding, peptic ulceration, haemorrhagic } \\
\text { cerebrovascular accident, renal impairment, } \\
\text { wheezing, rash }\end{array}$ \\
\hline Diuretics & $334(27.3)$ & $\begin{array}{l}\text { Furosemide (128), bendroflumethiazide (103), } \\
\text { bumetanide (43), spironolactone (37), amiloride (19), } \\
\text { metolazone (11), indapamide (6) }\end{array}$ & $\begin{array}{l}\text { Renal impairment, hypotension, electrolyte } \\
\text { disturbances, gout }\end{array}$ \\
\hline Warfarin & $129(10.5)$ & - & GI bleeding, haematuria, high INR, haematoma \\
\hline $\begin{array}{l}\text { ACE inhibitors/ } \\
\text { All receptor antagonists }\end{array}$ & $94(7.7)$ & $\begin{array}{l}\text { Ramipril (28), enalaparil (25), captopril (12), } \\
\text { lisinopril (9), irbesartan (6), losartan (5), perindopril (4) }\end{array}$ & $\begin{array}{l}\text { Renal impairment, hypotension, electrolyte } \\
\text { disturbance, angioedema }\end{array}$ \\
\hline Antidepressants & $87(7.1)$ & $\begin{array}{l}\text { Fluoxetine (17), paroxetine (14), amitriptyline (13), } \\
\text { citalopram (9), lithium (8), venlafaxine (8) dosulepin (7), }\end{array}$ & $\begin{array}{l}\text { Confusion, hypotension, constipation, Gl bleed, } \\
\text { hyponataemia }\end{array}$ \\
\hline$\beta$ blockers & $83(6.8)$ & $\begin{array}{l}\text { Atenolol (69), propranolol (6), sotalol (3), bisoprolol } \\
\text { (2), metoprolol (2), carvedilol (1) }\end{array}$ & Bradycardia, heart block, hypotension, wheezing \\
\hline Opiates & $73(6.0)$ & $\begin{array}{l}\text { Morphine (20), dihydrocodeine (20), co-codamol (8), } \\
\text { tramadol (8), co-dydramol (6), fentanyl (5) }\end{array}$ & Constipation, vomiting, confusion, urinary retention \\
\hline Digoxin & $36(2.9)$ & - & Symptomatic toxic digoxin levels \\
\hline Prednisolone & $31(2.5)$ & - & $\begin{array}{l}\text { Gastritis, GI bleeding, hyperglycaemia, osteoporotic } \\
\text { fracture }\end{array}$ \\
\hline Clopidogrel & $29(2.4)$ & - & GI bleeding \\
\hline
\end{tabular}

$\mathrm{Gl}=$ gastrointestinal, INR=international normalised ratio. 
hospital. Our analysis of hospital admissions related to ADRs suggests a $0.15 \%$ incidence of fatal ADRs, similar to the US figure. ${ }^{1}$ More recent data are needed to determine the prevalence of $\mathrm{ADR}$ after admission to hospital. In 2002 in England there were a total of 3.8 million acute admissions, ${ }^{29}$ suggesting that ADRs causing hospital admission are responsible for the death of 5700 patients (3800 to 7600 ) every year. The true rate of death taking into account all ADRs (those causing admission, and those occurring while patients are in hospital) may therefore turn out to be greater than 10000 a year.

Aspirin was identified as a causal agent in 18\% of cases of all admissions for ADRs, while other NSAIDs and diuretics were implicated in $12 \%$ and $27 \%$, respectively. This is consistent with results of previous studies. ${ }^{3}$ The finding that low dose aspirin was the most common drug implicated is relatively novel. However, caution has to be exercised in interpreting these data for two reasons: firstly, we do not have consumption data for these drugs, and the rank order of the implicated drugs may be a reflection of how commonly they are used. Secondly, we have concentrated on harms and have not taken into account the benefits of the drugs. This may be particularly true for drugs such as low dose aspirin, for which convincing data exist of the long terms benefits of prophylactic use in high risk patients. ${ }^{30}$ Nevertheless, measures that can further improve the benefit:harm ratio and avoid some of these ADRs need to be put into place. Our data would suggest that over $70 \%$ of the ADRs in this study were either possibly or definitely avoidable. Although we have used a previously described method, $^{20}$ its weakness is that it does require a degree of clinical judgment, which may have differed with other investigators. Nevertheless, it is consistent with recent data from France ${ }^{31}$ and the United Kingdom, ${ }^{13}$ which showed that $80 \%$ and $67 \%$ of ADRs, respectively, were preventable. It is also compatible with a recent meta-analysis, where the rate of preventable ADRs was $59 \%$ (interquartile range $50-73 \%$ ). ${ }^{23}$

\section{Improving benefit:harm ratio}

Given our findings and those in the literature, it is therefore incumbent on prescribers to determine the need for a particular drug in a patient and to use this drug at the lowest dose necessary to achieve benefit. Indeed, Langman has calculated that deaths related to aspirin could be reduced by $30 \%$ with the lower dose of $75 \mathrm{mg} .{ }^{32}$ However, even this dose can result in substantial morbidity and mortality, and other measures are needed. For example, regular use of proton pump inhibitors or misoprostol may be a cost effective method of reducing gastrointestinal adverse events associated with NSAIDs. ${ }^{26}$ Given that elderly people seem to be at higher risk of ADRs, many of the recommendations in the National Service Framework for the elderly need to be implemented. ${ }^{33}$ Simple measures such as regular review of prescriptions, the use of computerised prescribing, and the involvement of pharmacists in assessing prescribing behaviour may all reduce the burden caused by ADRs. In this respect, it is important to highlight that interactions accounted for one in six of the ADRs in this study.

In conclusion, ADRs are an important cause of hospital admissions, resulting in a considerable use of

\section{What is already known on this topic}

Adverse drug reactions (ADRs) account for $5 \%$ of hospital admissions, although this figure is largely based on small studies, many of which were performed before 1990

The incidence of fatal reactions in all patients admitted to hospital has been reported to be $0.13 \%$, but this is based on a meta-analysis of studies that were mostly performed several decades ago

\section{What this study adds}

ADRs continue to represent a considerable burden on the NHS, accounting for 1 in 16 hospital admissions and $4 \%$ of the hospital bed capacity

Most ADRs were predictable from the known pharmacology of the drugs and many represented known interactions and are therefore likely to be preventable.

Over $2 \%$ of patients admitted with an adverse drug reaction died, suggesting that adverse effects may be responsible for the death of $0.15 \%$ of all patients admitted

Older drugs continue to be most commonly implicated in causing such admissions

the NHS bed base, and a significant number of deaths. Many may be preventable through simple improvements in prescribing. We concentrated on ADRs causing hospital admissions and did not evaluate the burden caused by ADR occurring while patients are in hospital, or ADRs in primary care that did not result in hospital admission, which may at least double the figures presented here. Measures are urgently needed to reduce the burden on the NHS.

We thank June Raine (MHRA) for her encouragement and assistance with this study, all staff in both hospitals who assisted with the study, and, in particular, S Roberts, S MorrisonGriffiths, and R Brady for their help in identifying case notes and in data extraction.

Contributors: MP, TJW, BKP, and AMB devised the idea of the study, while MP and AMB raised funding. MP oversaw the whole study. SJ and SM collected the data and input the data into databases. AKS, CG, and KF were responsible for study implementation, and review and supervision of the data collection in hospital B; MP and AMB undertook the same roles in hospital A. The analyses were carried out independently by MP and SJ, and verified by TJW. MP produced the first draft, and all authors contributed to the final draft of the manuscript. MP is guarantor for the study.

Funding: The study was funded by the MHRA (Medicines and Healthcare Products Regulatory Agency; formerly the Medicines Control Agency). The MHRA had no role in data interpretation or in the production of this manuscript.

Competing interests: At the time of the study, AMB was chairman of the Committee on Safety of Medicines and now is chairman of the MHRA. MP is a member of the Committee on Safety of Medicines and of the subcommittee on pharmacovigilance. BKP is a member of the Committee on Safety of Medicines.

Ethical approval: Liverpool Local Research Ethics Committee and Wirral Health Authority Research Ethics Committee. 
1 Lazarou J, Pomeranz BH, Corey PN. Incidence of adverse drug reactions in hospitalized patients - a meta-analysis of prospective studies. JAMA 1998:279:1200-5

2 Kvasz M, Allen IE, Gordon MJ, Ro EY, Estok R, Olkin I, et al. Adverse drug reactions in hospitalized patients: a critique of a meta-analysis. MedGenMed 2000;2:E3

3 Wiffen P, Gill M, Edwards J, Moore A. Adverse drug reactions in hospital patients. A systematic review of the prospective and retrospective studies. Bandolier Extra 2002; June:1-16.

4 Ghose K. Hospital bed occupancy due to drug-related problems.J $R$ Soc Med 1980;73:853-6.

5 Gosney M, Tallis R. Prescription of contraindicated and interacting drugs in elderly patients admitted to hospital. Lancet 1984;ii:564-7.

6 Hurwitz N. Admissions to hospital due to drugs. BMJ 1969;i:539-40.

7 Hurwitz N. Predisposing factors in adverse reactions to drugs. $B M J$ 1969;i:536-9.

Hurwitz N, Wade OL. Intensive hospital monitoring of adverse reactions to drugs. BMJ 1969;i:531-6.

9 Leach S, Roy SS. Adverse drug reactions: an investigation on an acute geriatric ward. Age Ageing 1986;15:241-6.

10 Williamson J, Chopin JM. Adverse reactions to prescribed drugs in the elderly: a multicentre investigation. Age Ageing 1980;9:73-80.

11 Lindley CM, Tully MP, Paramsothy V, Tallis RC. Inappropriate medication is a major cause of adverse drug reactions in elderly patients. Age Ageing 1992;21:294-300.

12 Smith CC, Bennett PM, Pearce HM, Harrison PI, Reynolds DJ, Aronson $\mathrm{JK}$, et al. Adverse drug reactions in a hospital general medical unit meriting notification to the Committee on Safety of Medicines. Br J Clin Phar macol 1996;42:423-9.

13 Howard RL, Avery AJ, Howard PD, Partridge M. Investigation into the reasons for preventable drug related admissions to a medical admissions unit: observational study. Qual Saf Health Care 2003;12:280-5.

14 Bhalla N, Duggan C, Dhillon S. The incidence and nature of drug-related admissions to hospital. Pharmaceutical J 2003;270:583-6.

15 Edwards IR, Aronson JK. Adverse drug reactions: definitions, diagnosis, Edwards IR, Aronson JK. Adverse drug reaci

16 British Medical Association, Royal Pharmaceutical Society of Great Britain. British national formulary. London: BMA, RPS, 2002 (No 44).

17 Naranjo CA, Busto U, Sellers EM, Sandor P, Ruiz I, Roberst EA, et al. A method for estimating the probability of adverse drug reactions. Clin Pharmacol Ther 1981;30:239-45

18 Jones JK. Adverse drug reactions in the community health setting: approaches to recognizing, counseling, and reporting. Fam Community Health 1982;5:58-67.
19 Rawlins MD, Thompson JW. Mechanisms of adverse drug reactions. In: Davies DM, ed. Textbook of adverse drug reactions. Oxford: Oxford University Press, 1991:18-45

20 Hallas J, Harvald B, Gram LF, Grodum E, Prosen K, Haghfelt T, et al. Drug related hospital admissions: the role of definitions and intensity of data collection, and the possibility of prevention. J Intern Med 1990;228:83-90

21 Chartered Institute of Public Finance and Accountancy (CIPFA). The health service financial database and comparative tool. Croydon: Institute of Public Finance, 2002.

22 Einarson TR. Drug-related hospital admissions. Ann Pharmacother 1993;27:832-40

23 Winterstein AG, Sauer BC, Hepler CD, Poole C. Preventable drug-related hospital admissions. Ann Pharmacother 2002;36:1238-48.

24 Beijer HJ, de Blaey CJ. Hospitalisations caused by adverse drug reactions (ADR): a meta-analysis of observational studies. Pharm World Sci 2002;24:46-54.

25 Weil J, Colin-Jones D, Langman M, Lawson D, Logan R, Murphy M, et al. Prophylactic aspirin and risk of peptic ulcer bleeding. BMJ 1995;310:82730.

26 Rodriguez-Monguio R, Otero M, Rovira J. Assessing the economic impact of adverse drug effects. Pharmacoeconomics 2003;21:623-50.

27 Bates DW, Spell N, Cullen DJ, Burdick E, Laird N, Petersen LA, et al. The costs of adverse drug events in hospitalized patients. JAMA 1997:277:307-11.

28 Classen DC, Pestotnik SL, Evans RS, Lloyd JF, Burke JP. Adverse drug events in hospitalized patients. Excess length of stay, extra costs, and tributable mortality. JAMA 1997:277:301-6.

29 Department of Health. Hospital episode statistics 2001-2. www.doh.gov.uk/hes/free_data/index.html (accessed 13 Nov 2003).

30 Gaspoz JM, Coxson PG, Goldman PA, Williams LW, Kuntz KM, Hunink MG, et al. Cost effectiveness of aspirin, clopidogrel, or both for secondary prevention of coronary heart disease. N Engl J Med 2002;346:1800-6.

31 Lagnaoui R, Moore N, Fach J, Longy-Boursier M, Begaud B. Adverse drug reactions in a department of systemic diseases-oriented internal medicine: prevalence, incidence, direct costs and avoidability. Eur J Clin Pharmacol 2000;56:181-6.

32 Langman MJ. Ulcer complications associated with anti-inflammatory drug use. What is the extent of the disease burden? Pharmacoepidemiol Drug Saf 2001:10:13-9.

33 Department of Health. Medicines for older people: implementing medicinesrelated aspects of the NSF for older people. London: Department of Health, 2001.

(Accepted 11 June 2004)

\section{Systematic review of the incidence and consequences of uterine rupture in women with previous caesarean section}

Jeanne-Marie Guise, Marian S McDonagh, Patricia Osterweil, Peggy Nygren, Benjamin K S Chan, Mark Helfand

\begin{abstract}
Objective To evaluate the incidence and consequences of uterine rupture in women who have had a delivery by caesarean section.

Design Systematic review.

Data sources Medline, HealthSTAR, Cochrane Database of Systematic Reviews, Cochrane Controlled Trials Register, National Centre for Reviews and Dissemination, reference lists, and national experts. Studies in all languages were eligible if published in full. Review methods Methodological quality was evaluated for each study by using criteria from the United States Preventive Services Task Force and the National Health Service Centre for Reviews and Dissemination. Uterine rupture was categorised as asymptomatic or symptomatic.

Results We reviewed 568 full text articles to identify 71 potentially eligible studies, 21 of which were rated at least fair in quality. Compared with elective repeat caesarean delivery, trial of labour increased the risk of uterine rupture by 2.7 (95\% confidence interval 0.73 to 4.73 ) per 1000 cases. No maternal deaths were
\end{abstract}

related to rupture. For women attempting vaginal delivery, the additional risk of perinatal death from rupture of a uterine scar was 1.4 (0 to 9.8) per 10000 and the additional risk of hysterectomy was 3.4 (0 to 12.6) per 10000 . The rates of asymptomatic uterine rupture in trial of labour and elective repeat caesarean did not differ significantly.

Conclusions Although the literature on uterine rupture is imprecise and inconsistent, existing studies indicate that 370 (213 to 1370) elective caesarean deliveries would need to be performed to prevent one symptomatic uterine rupture.

\section{Introduction}

In the past 20 years, trial of labour has been encouraged for women who have had a caesarean delivery. Recent studies reporting that mother and

This is an abridged version; the full version is on bmj.com

A table with details of included studies is on bmj.com
Department of Obstetrics and Oregon Health \& Science University, UHN-50, $3181 \mathrm{SW}$ Sam Jackson Park Road, Portland, OR 97239-3098, USA

Jeanne-Marie Guise assistant professor

Evidence-based Practice Center, Oregon Health \& Science University

Marian S

McDonagh assistant professor

Patricia Osterweil research assistant

Peggy Nygren

senior research

Benjamin K S Chan senior research

associate

Mark Helfand director

Correspondence to: J-M Guise guisej@ohsu.edu

BMJ 2004;329:19-23 